Check for updates

Independent Food Aid Network

Cite this as: BMJ 2022;376:0416 http://dx.doi.org/10.1136/bmj.0416 Published: 16 February 2022

\title{
Food aid charities fear the worst as the cost of living crisis takes hold
}

\section{Sabine Goodwin coordinator}

At an Independent Food Aid Network member meeting last week, it was clear that things were getting worse, much worse. ${ }^{1}$ The perfect storm that emerged last October is rapidly turning into a flood of need at the doors of food aid charities. ${ }^{2}$ On top of the end to the $£ 20$ Universal Credit uplift, people on low incomes are now struggling with soaring bills and food prices, with a massive increase in energy prices and National Insurance contribution rises just around the corner. These drivers of poverty inevitably mean yet more people on low incomes are needing, and will need, to turn to food banks to survive.

It's deeply troubling for our members to know that the number of people seeking their help will continue to surge. Food bank teams are physically and mentally exhausted after supporting people for months on end through the pandemic. They don't necessarily have the resources to cope with the waves of need on the horizon-food donations have reduced as has volunteer capacity. Some members are reporting cases of people who used to donate now needing to access their support. Volunteers cannot be expected to cope with the scale of distress they are regularly witnessing.

Alexandra McMillan of the Legendary Community Club based in Lewisham explains: "People are worrying and already finding it a struggle. I have no answers for them and it's extremely concerning as the hole is getting deeper and deeper and there isn't a way out right now." And Lianne Simpson of Diamond Hampers in Huntingdonshire says: "I have seen a rising concern over the battle to heat the home or put food on the table. I am seeing people so upset because, even if they are provided with food, they have no ability to cook it."

Kate Brewster of the One Can Trust in Buckinghamshire says: "Numbers at our food bank are increasing at the highest rate we've known. Current levels, from the beginning of February, are around double those six months ago. In the last couple of weeks, we've helped more than 700 people and around half of those are children. We dread to think what's round the corner. It's heart-breaking."

People impacted by poverty for the first time are seeking help as well as people caught in entrenched, chronic poverty. As Joe Scrase of the Bay Foodbank in North Shields puts it: "We're seeing return clients reaching a new level of extreme poverty that is beyond Dickensian.”

People who might have managed to get by a few months ago now have nowhere else to turn. Joyce Leggate of Kirkcaldy Foodbank in Fife says: "What we are seeing is people we hadn't seen for almost a year coming back and saying their budget just doesn't go as far these days.”
It's also striking to learn of the numbers in work who now need to access charitable food aid. Charlotte White of Earlsfield Foodbank in Wandsworth explains: "We're concerned about how people in work need to access help-in the past most of our guests were unemployed, but this really isn't the case anymore. Recently we had a session where $50 \%$ of our guests had work of some kind."

We're frequently hearing of the disproportionate impact that the crisis is having on single people. Lester Tanner of Maidenhead Foodshare explains: "Living alone can be tough in terms of isolation and loneliness; now many are having to deal with the pressures and anxieties of their essential expenses outstripping their income."

Against this backdrop of rising demand, our members are already having to reduce the size and diversity of their food parcels. Annie McCormack of Broke not Broken in Kinross explains: "As April approaches, we are having to make difficult decisions. We're reducing the amount of food in a parcel and the amount we give in supermarket vouchers."

The measures announced recently by the chancellor barely scratch the surface of the financial crises faced by low income households. Levels of destitution and extreme poverty are undoubtedly on the rise, and this is affecting people of all ages. The long term impact on people's physical and mental health of this immediate crisis alone will clearly be devastating and what we are learning through food banks is only the tip of the iceberg. Recent Food Standards Agency data show that $4 \%$ of people in England, Wales, and Northern Ireland used a food bank in the 12 months up to June 2021 , but $15 \%$ of people went hungry or reduced their food intake due to lack of income. ${ }^{3}$ Simon Lellow of Telford Crisis Support in Telford and Wrekin points out: “The long term impact of subsisting within this environment is wholly detrimental to individuals, families, and society."

The government must do a great deal more to ensure that incomes, whether through social security payments or wages, match the rising cost of living. At the very least, social security payments must be uprated in line with inflation, wages increased, and immediate, targeted cash first support put in place in every local authority.

\section{Competing interests: none declared \\ Provenance and peer review: commissioned, not peer reviewed}

BMJ readers raised more than $£ 60000$ on behalf of the Independent Food Aid Network (IFAN) during the BMJ 2020/21 Annual Appeal. IFAN supports, connects, and advocates on behalf of a range of food aid providers including over 550 independent food banks. BMJ readers' donations went directly to frontline member organisations and supported IFAN's work to co-develop cash first referral leaflets in multiple local authorities across the UK. 
2 Goodwin S. Food poverty set to worsen as September's Universal Credit cliff edge approaches. BMJ Opinion. https://blogs.bmj.com/bmi/2021/08/26/food-poverty-set-to-worsen-as-septembersuniversal-credit-cliff-edge-approaches/

3 https://www.food.gov.uk/research/food-and-you-2/food-and-you-2-wave-3 